\title{
Las novelas de la oligarquía chilena de Grínor Rojo
}

Santiago, Chile: Sangría Editores, 2011, 276 páginas.

Cristián Montes

Universidad de Chile. Santiago, Chile cmontes@vtr.net

Según plantea Grínor Rojo, tal como puede apreciarse en la Introducción

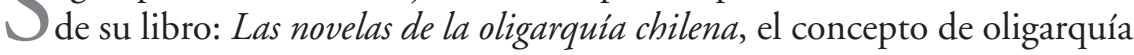
rebasa ampliamente el tema del poder económico concentrado en un determinado grupo social, para remitir, más bien, a un ámbito de individuos portadores de un poder de carácter simbólico. El autor señala su concordancia con los planteamientos de Cornelius Castoriadis, en cuanto a que el carácter de tal sustrato simbólico puede definirse como un imaginario, entendiendo por esto una concepción de mundo a partir de la cual se procesa y reelaboran los contenidos de la realidad. Toda sociedad puede entenderse así como un sistema de interpretaciones que crean dicho mundo. Tal como plantea Gilbert Durán, quien aunque no citado por Rojo pareciera estar también en el trasfondo de sus reflexiones, toda configuración cultural es finalmente una expresión de un régimen imaginario. En consecuencia, las tesis del libro estarán orientadas a visualizar cómo el imaginario oligárquico es modelizado desde la ficción y de qué forma opera como un dispositivo generador de mundos posibles.

El corpus de novelas escogido dibuja un arco temporal que va desde 1908 hasta 2009. En esta amplia tesitura histórico-temporal el análisis literario mostrará el diálogo fructífero entre la literatura y los contextos sociales de producción. Podrán apreciarse en este desarrollo las características, continuidades y discontinuidades del imaginario oligárquico y las formas cómo éste se reelabora desde la especificidad del discurso narrativo.

La primera de las novelas chilenas seleccionada es Casa grande de Orrego Luco, publicada en 1908, en torno a la cual se plantea que el sentido general del texto radica en el llamado de atención que se hace a la clase oligárquica, por haber descuidado las responsabilidades de su antiguo y natural liderazgo. La función de dirección del discurso narrativo estaría enfocado, enton- 
ces, a que esta clase de antiguo abolengo y pureza de sangre, la que ha estado sumida en preocupaciones frívolas y triviales, vuelva a ser lo que siempre ha sido, es decir, una casta connaturalmente superior e irremplazable.

El desarrollo del imaginario oligárquico se matiza con otra novela representativa como es La chica del Crillón, de 1935, escrita por Joaquín Edwards Bello. La mirada crítica se concentra de manera particular en el contexto histórico de la época en que se escribió la novela y se visualizan los modos en que el discurso autorial y el autor real proyectan en el personaje central sus propias convenciones, su problemática subjetividad y una crítica a un orden al cual el mismo Joaquín Edwards Bello pertenece. La representación de mundo permite apreciar cómo en un período signado por constantes rebeliones sociales, se erige una imagen de mujer en la cual la independencia y el deseo de autonomía serán su característica fundamental. El imaginario oligárquico se define aquí por un soporte ideológico desde el cual se evidencia el rechazo que dicha casta tiene por los advenedizos y siúticos que piensan que el éxito económico los puede hacer ingresar a un ámbito donde lo esencial radica en otro tipo de valores. Fundamental en esta ligazón con lo originario y la tradición de estirpe es el ser dueño de una considerable extensión de tierras.

Un importante matiz de diferencia en la constitución del imaginario de la oligarquía nacional se encuentra en la novela criollista Gran señor y rajadiablos de Eduardo Barrios, publicada en 1948. El sustrato oligárquico evidencia aquí una visión de mundo donde se organiza y justifica un orden social caracterizado por la exclusión y el dominio de unos sobre otros. El discurso de ideas de la novela permite visualizar la resistencia de esta capa oligárquica a cualquier tipo de cambio que pueda amenazar su poderío simbólico. Dentro de ese conservadurismo congénito, el texto deja al descubierto su incomodidad contra los efectos de la modernización que se venían desarrollando desde finales del siglo XIX y comienzos del XX.

Cabe destacar que el análisis realizado por Grínor Rojo no se limita a dar cuenta de cómo se expresa el imaginario de la oligarquía en cada una de las novelas analizadas, sino también permite detectar las similitudes y diferencias que pueden apreciarse. Por ejemplo, respecto a Casa Grande, La chica del Crillón y Gran señor y rajadiablos, se afirma que, a pesar de la distancia temporal que separa a tales novelas, "las tres tienen como punto de arranque el convencimiento de que en la historia de la fracción oligárquica chilena hubo una era de gloria y que esa era de gloria se marchó, a lo peor para no volver" (98).

La cuarta novela escogida para mostrar la evolución del imaginario oli- 
gárquico es Este domingo de José Donoso, cuya publicación data de 1966. Se observa aquí una importante inflexión en lo relativo al imaginario desplegado, puesto que en la condición oligárquica del siglo XX la tierra no será ya una realidad concreta sino que tendrá un carácter meramente simbólico. En vez del campo, la focalización narrativa se concentra en el espacio concreto de la casa donde habitan los personajes, significante privilegiado que se erige como metáfora y metonimia de la realidad nacional y del orden social que lucha por perpetuarse. En Este domingo se vuelve nítida la manera cómo la oligarquía chilena se ve e interpreta a sí misma en el curso de la historia del país. Lo que queda inscrito en el texto es la degradación de un mundo donde parece imposible una relación solidaria y constructiva entre los diversos grupos que conforman el tejido social: resabios de la odiosa oposición entre quienes ostentan los valores de la civilización occidental y los que transgreden y desestabilizan dicho orden social.

Una constante que se observa, según Rojo, en las novelas de Luis Orrego Luco, Joaquín Edwards Bello, Eduardo Barrios e incluso José Donoso, es el contraste que se observa entre el sector oligárquico y el capitalista. Se evidencia aquí la importancia de la sangre y del buen gusto supuestamente connatural a ese grupo, aspecto que estas novelas parecen querer transferir al lector de su tiempo; una especie de intencionalidad de estos textos, para utilizar un término de Eco, donde dicha "superioridad" necesita ser validada por los lectores. En todas estas novelas se aprecia igualmente la importancia de la tierra como elemento de distinción a partir del cual se organiza el poder social.

El imaginario oligárquico sufre un cambio de significación estructural en la novela Oír su voz de Arturo Fontaine Talavera, publicada en 2009. Acorde a los cambios sociales e históricos, la tierra pierde en definitiva su estatus de referente material y simbólico. En tiempos posteriores a la reforma agraria, la oligarquía deja traslucir su añoranza por un pasado glorioso que debe asumir que los años del régimen dictatorial han generado transformaciones definitivas en el ámbito económico y las relaciones humanas. En Oír su voz el grupo oligárquico representa fundamentalmente a quienes son dueños del poder económico y a quienes ven en dicho poder la vía para legitimarse como sujetos. Lo conforman los empresarios, los tecnócratas, los medios de comunicación, los militares, los operadores económicos y también el selecto grupo de artistas e intelectuales que viven fuera de Chile y por eso ignoran lo que pasa en el país. En coherencia con la imagen de mundo desplegada, el motivo narrativo que produce el transcurrir de la diégesis remite ficcionalmente a la crisis económica que en los años 80 afectó a Chile y que pulverizó 
el supuesto milagro económico.

Por último, en la novela Vendo casa en el barrio alto, de Elizabeth Subercaseux, publicada en 2009, se refuerza la idea de que la casta oligárquica continúa vigente y se ha adecuado a los tiempos del neoliberalismo y globalización imperante. Al igual que lo que ocurre en la novela de Fontaine, la tierra y su posesión ya no son condición para formar y sentirse parte de una elite privilegiada. El poderío económico ha distribuido a los personajes en diversas actividades y lugares como el gobierno, la bolsa de comercio, las corredoras de propiedades y todo un conjunto de epicentros donde el éxito y el posicionamiento social se aquilatan y definen. En una ciudad fragmentada y estratificada, el gran signo de estatus es ahora el barrio y la casa donde se vive. "Dime dónde vives y te diré quién eres", es la consigna y el ideologema que concentra una concepción valórica eminentemente economicista y excluyente. Sin embargo, y a pesar de lo anterior, la perspectiva semántica del texto posibilita ver una constante que el análisis de Grínor Rojo ha percibido operando desde La casa Grande de Orrego Luco, esto es, la conciencia de la oligarquía de que no es el dinero lo que finalmente la define, sino una cuestión de abolengo y sangre. La clase social, la verdadera clase, no es algo que puede adquirirse con dinero. Como dice uno de los personajes, Gregorio Vial Correa, "se nace con ella o sin ella".

Con el análisis de esta novela concluye el texto crítico de Grínor Rojo, en cuyo desarrollo ha podido quedar demostrado la presencia e incidencia del imaginario que la oligarquía chilena ha dejado inscrito en el ámbito de la narrativa chilena. El análisis ha permitido apreciar que dicho imaginario no ha desaparecido en el transcurrir del tiempo, sino que se ha mantenido vigente desde comienzos del siglo XX hasta los tiempos del neoliberalismo y la globalización. Se trata de un imaginario o constructo ideológico donde los agentes se han pensado siempre a sí mismos como parte de una elite privilegiada por antonomasia y han tenido la astucia de irse adecuando a los tiempos. El concepto de ideología activado aquí remite, en términos de Marx, a un conjunto de ideas generadas, desarrolladas y movilizadas por la clase dominante y en pos de sus propios intereses. Como puede apreciarse en el análisis de Grínor Rojo, el concepto de imaginario se fusiona aquí con el de sustrato ideológico, cuyo fin, en términos de lo que plantea Terry Eagleton, ha sido siempre intentar naturalizar la realidad social, hasta hacerla aparecer tan invariable como la naturaleza.

Respecto a la genealogía del pensamiento teórico en la cual se inserta el posicionamiento crítico de Grínor Rojo, hay una línea de pensamiento que es la más evidente. Para comenzar, puede afirmarse que en su análisis se ob- 
serva una atención especial en tres frentes de significación: atender al modo general de producción dominante en el contexto socio-cultural donde las obras fueron gestadas, visualizar las formas cómo la producción literaria de cada período se relaciona con determinadas formaciones sociales y definir los discursos que cruzan los textos, desplegando, al mismo tiempo, la ideología que en ellos subyace.

Una de las referencias teóricas fundamentales dentro de la genealogía que opera como sustrato teórico en el posicionamiento crítico de Rojo es el pensamiento de Lukács respecto a la novela. Elocuente, al respecto, es la apreciación valorativa que hace de la novela de Elizabeth Subercaseux: Vendo casa en el barrio alto, en cuanto en ésta se alcanza lo que Lukács define como tipo y "se reivindica la categoría de la particularidad, poniéndola entre la pura generalidad, con la que entablaría una justa dialéctica, y la pura singularidad, a la que Lukács desdeña”. Esta matriz de pensamiento reactivada en la perspectiva del análisis, y que está de alguna forma presente transversalmente en su libro, le otorga una particular relevancia al concepto de tipo. Es necesario recordar que para Lukács el reflejo dialéctico que toda obra debiera alcanzar se produce únicamente cuando lo típico y la esencia están ligados entre sí. Ello se logra gracias a que el conocimiento estético liga ambas categorías, abandonándose de esa forma el marco de la inmediatez naturalista. Para evitar los peligros del reflejo naturalista, la elaboración estética debe desprenderse de lo unilateralmente casual y particular, sin descuidar la esfera de lo individual. Para Lukács, la solución radica justamente en lo que define como tipo, es decir ese "ámbito intermedio en el que se aglutina una significación generalizada de la individualidad de los hombres, situaciones, actos, etc., sin superar por ello su individualidad, sino precisamente intensificándola”.

Por otro lado, la estrategia interpretativa activada por Rojo logra perfilar con solvencia el horizonte de expectativas de la época en que los textos fueron escritos, horizonte puesto siempre en diálogo con el punto de hablada del crítico. Se procesan desde un presente desde donde se interpreta las formas cómo en su tiempo dichos textos fueron procesados, lográndose así lo que Bajtin define como "plenitud factual", entendiendo por ello el diálogo fructífero entre el tiempo de la obra, sus lectores, su autor y el presente complejo desde el que se lee y se procesa ese objeto literario.

El estudio realizado por Grínor Rojo no parece congeniar con los enfoques inmanentistas del texto. Al contrario, su tendencia es desplegar e interpretar el estado de la sociedad y los enclaves históricos responsables de la materia compleja que nutre toda ficción literaria. En este sentido, su 
estrategia crítica posee un sesgo arqueológico-literario, en cuanto saca a luz lo que Noé Jitrik define como el genotexto de los textos, es decir, la situación histórica-política-cultural desde la cual se generan dichos productos simbólicos. Dicha estrategia posibilita, por lo mismo, visualizar el diálogo fructífero que la literatura entabla siempre con su tiempo.

Se observa también aquí una concordancia entre el procedimiento realizado por Rojo y algunos planteamientos de Pierre Macherey en cuanto a la necesidad de trabajar con los contenidos implícitos y latentes del texto analizado. Al igual que lo que propone Macherey, Rojo pareciera concordar en que explicar una obra exige captarla en su descentramiento efectivo, es decir, en vislumbrar qué es lo que le falta, en qué radica su ausencia. Lo que no pudo decir o nombrar es justamente el sustrato histórico responsable de su existencia como obra de arte.

Cabe destacar, en todo caso, que lo mencionado hasta aquí no significa que el análisis que realiza Grínor Rojo no considere la autonomía que posee el objeto literario. Todo lo contrario, la especificidad de lo literario es siempre una dimensión presente en su enfoque crítico. Su análisis entra en consonancia con los planteamientos de Lucien Goldman, quien señala, en consecuencia con los planteamientos de su maestro Lukács, que una obra literaria es, en primer lugar, al igual que todo hecho humano, una estructura comprensiva. Por tal razón debe primeramente estudiarse cómo está conformada y cuáles son los elementos que la componen, lo que significa establecer una descripción rigurosa de su composición y su función interna. En lo que respecta al análisis de Rojo, es constante su atención a la figura de los narradores, a las funciones ideológicas que portan, al tipo de función que sus discursos despliegan, al plano de los personajes, al nivel psicológico, y a todo el conjunto de elementos que configuran el objeto literario desde su constitución interna. Sólo después la mirada del crítico verá como están activados en el texto literario los contextos de producción y la esfera ideológica. Es en esos momentos donde el análisis se eleva a otro nivel, que Lucien Goldman define como el proceso de explicación de la obra. Explicar una obra y no sólo comprenderla implica descubrir y describir la estructura mayor en que la estructura significativa que se estudia tiene una función. El supuesto teórico aquí presente es que toda creación cultural debe estudiarse en relación a la vida global de la sociedad y que existe una íntima vinculación entre las leyes que rigen la creación cultural y las que regulan el comportamiento social y económico.

Tal vez el último eslabón en esta genealogía teórica con la que dialoga el trabajo de Grínor Rojo es con lo que se ha definido como la sociocrítica, 
especialmente a partir de los teóricos canadienses Marc Angenot y Regine Robin. En consecuencia con lo mencionado, el análisis textual de Grínor Rojo logra visualizar las formas de cómo se inscribe el discurso social en los textos literarios. Al igual que lo que plantea la sociocrítica, el análisis crítico realizado ha escenificado las distintas modalidades en que las novelas estudiadas expresan y tematizan lo real a partir de los diversos lenguajes, discursos y formas culturales. Su análisis, y eso es uno de los imperativos de la sociocrítica, "logra reconstruir las reglas de formación de los discursos y las maneras de hablar de un estado de la sociedad que determina lo legítimo discursivo de cada época".

Finalmente, y remitiéndome ahora al aspecto compositivo del libro de Grínor Rojo, quisiera señalar que un rasgo particular de la escritura crítica de Rojo es el exponer de manera explícita sus preconcepciones y valoraciones en el análisis crítico. Subyace aquí el supuesto de que toda investigación parte de un número de posturas y valorizaciones y que éstas deben estar presentes en el análisis. En este sentido es un crítico que no oculta sus preferencias o rechazos sino que los expone como parte relevante de su arsenal interpretativo. Elocuente, por ejemplo, es su rechazo a la concepción de mundo que se desprende de la novela de Eduardo Barrios: "Gran señor y rajadiablos contiene todos y cada uno de los elementos que a mí me resultan detestables en las producciones simbólicas no importa cuál sea su receptáculo semiótico" (89) o más adelante y refiriéndose a la conciencia estructurante o autor implícito: "esa figura es racista, es clasista, es sexista, es abusiva con los débiles, es políticamente corrupta, religiosamente intolerante, chauvinista cerril y un largo, un larguísimo etcétera” (90).

Los juicios de valor no se limitan únicamente a la configuración de los mundos fictivos sino también a la constitución misma del género novela. Se accede así, por lo mismo, a los parámetros desde donde se fragua su mirada crítica. Esto se evidencia, por ejemplo, en el análisis de Oír su voz de Arturo Fontaine Talavera, cuando afirma que en una buena novela moderna debe haber necesariamente una distancia irónica o cuando señala que "el lenguaje de la novela es siempre lenguaje de lo particular y no porque acarree la carga de lo verdadero inapelable, sino por su apuesta a las virtudes reveladoras de la verosimilitud".

Además del sólido aporte de Grínor Rojo a la crítica literaria en Chile, su libro tiene además el mérito de trabajar el tema del imaginario oligárquico en un corpus extenso y productivo. Ello permite apreciar la evolución de dicho imaginario no sólo en el devenir de la producción literaria, sino también en la trama social que la nutre de significación. Hasta hoy día podían encon- 
trarse únicamente estudios parcelados sobre algunos de los textos analizados en este libro, lo cual no permitía estudiar ni la evolución del imaginario de la oligarquía ni tampoco entender realmente en qué consiste su particular y escurridiza impronta. El libro de Grínor Rojo vino, por suerte, a llenar ese vacío. 